\title{
Ratios of anti-factor Xa to antithrombin activities of heparins as determined in recalcified human plasma
}

Citation for published version (APA):

Schoen, P., Lindhout, T., \& Hemker, H. C. (1992). Ratios of anti-factor Xa to antithrombin activities of heparins as determined in recalcified human plasma. British Journal of Haematology, 81(2), 255-262. https://doi.org/10.1111/j.1365-2141.1992.tb08217.x

Document status and date:

Published: 01/01/1992

DOI:

10.1111/j.1365-2141.1992.tb08217.x

Document Version:

Publisher's PDF, also known as Version of record

\section{Please check the document version of this publication:}

- A submitted manuscript is the version of the article upon submission and before peer-review. There can be important differences between the submitted version and the official published version of record.

People interested in the research are advised to contact the author for the final version of the publication, or visit the DOI to the publisher's website.

- The final author version and the galley proof are versions of the publication after peer review.

- The final published version features the final layout of the paper including the volume, issue and page numbers.

Link to publication

\footnotetext{
General rights rights.

- You may freely distribute the URL identifying the publication in the public portal. please follow below link for the End User Agreement:

www.umlib.nl/taverne-license

Take down policy

If you believe that this document breaches copyright please contact us at:

repository@maastrichtuniversity.nl

providing details and we will investigate your claim.
}

Copyright and moral rights for the publications made accessible in the public portal are retained by the authors and/or other copyright owners and it is a condition of accessing publications that users recognise and abide by the legal requirements associated with these

- Users may download and print one copy of any publication from the public portal for the purpose of private study or research.

- You may not further distribute the material or use it for any profit-making activity or commercial gain

If the publication is distributed under the terms of Article $25 \mathrm{fa}$ of the Dutch Copyright Act, indicated by the "Taverne" license above, 


\title{
Ratios of anti-factor Xa to antithrombin activities of heparins as determined in recalcified human plasma
}

\author{
Pieter Schoen, * Theo Lindhout and H. Coenraad Hemker Department of Biochemistry, \\ Cardiovascular Research Institute, University of Limburg, Maastricht, The Netherlands
}

Received 30 September 1991; accepted for publication 24 January 1992

\begin{abstract}
Summary. Anti-factor $\mathrm{Xa}$ and anti-thrombin activities of unfractionated (UF) and low molecular weight (LMW) heparins have been measured in human plasma and with purified human antithrombin III (ATII) in the absence and presence of $1.5 \mathrm{~mm}$ calcium. The anti-factor Xa and antithrombin activities were measured directly, by assessing the heparin-dependent pseudo-first order rate constants of inactivation of human factor Xa or thrombin. These activities were studied with the 4th International Standard for UF heparin, the 1st International Standard for LMW heparin, CY216. enoxaparin, CY222, and the synthetic pentasaccharide. In plasma, calcium equally well increased the specific antifactor Xa catalytic activities as compared to purified ATIII. That is, $1.5 \mathrm{~mm}$ calcium stimulated the UF standard heparincatalysed inactivation of factor Xa $2 \cdot 1-2 \cdot 4$ times. In the
\end{abstract}

presence of the LMW heparins the effect of calcium was smaller $(1 \cdot 3-1 \cdot 7$ times), and in plasma there was no effect of calcium on the pentasaccharide-catalysed inactivation of factor Xa. Thus, the largest effects of calcium in the inactivation reaction of factor Xa is seen with UF standard heparin. Calcium reduced the anti-thrombin activities of all the heparin preparations studied about 1.5 times when purified ATIII was used, although in plasma this effect was less clear. Consequently, in the presence of $1.5 \mathrm{~mm}$ calcium the ratio of the anti-factor $\mathrm{Xa}$ to the anti-thrombin activities of UF standard heparin approximated those of the LMW heparins. The only exception was CY222, which under all conditions retained anti-factor $\mathrm{Xa} /$ anti-thrombin ratios significantly higher than those of UF standard heparin.
One of the regulatory mechanisms of blood coagulation is the inhibition of enzymes of the coagulation system by the plasma protein antithrombin III (ATII), its main targets in clotting plasma being thrombin and factor Xa (Harpel, 1987). Inactivation of these serine proteases is catalysed by heparin, and thus the heparin-dependent anti-factor Xa and anti-thrombin activities have become main points of interest in studying the mode of action and the standardization of heparin. It should also be noted here, however, that the ATIII-dependent inactivation of free factor IXa can contribute significantly to the heparin effect in clotting plasma (Béguin et al, 1991).

Since 1976 it is known that low molecular weight (LMW) heparin fractions have little effect on tests of overall clotting, such as the activated partial thromboplastin time (APTT), but

* Present address: Laboratory of Physiological Chemistry, University of Groningen, Bloemsingel 10, $9712 \mathrm{KZ}$ Groningen, The Netherlands.

Correspondence: $\mathrm{Dr}$ Th. Lindhout, Department of Biochemistry, University of Limburg, P.O. Box 616, 6200 MD Maastricht, The Netherlands. maintain their potency as measured by anti-factor Xa assays (Andersson et al, 1976; Lane et al, 1978; Barrowcliffe et al, 1979). Studies on the structure-function relationship of heparin have learned that a pentasaccharide sequence, necessary for the interaction with ATIII, is sufficient to obtain catalysis of the inactivation of factor Xa (Choay, 1989). The heparin-catalysed inactivation of thrombin is dependent on the simultaneous binding of both proteins, which requires a heparin chain length of at least 18 saccharide units (Lane et al, 1984; Danielsson et al, 1986). LMW heparin preparations consist of chains with a length of 2-30 saccharides. Thus they contain considerable amounts of material without antithrombin activity, and therefore their lower anticoagulant activities in APTT-like tests are thought to be caused by reduced anti-thrombin specific activities. Subsequently, it has become generally accepted that LMW heparin preparations differ from unfractionated (UF) heparin preparations by significant higher anti-factor $\mathrm{Xa}$ to anti-thrombin ratios.

At present (LMW) heparin-dependent anti-factor Xa and anti-thrombin activities are mostly assessed in a nonrecalcified citrated plasma milieu, because factor $\mathrm{Xa}$ and thrombin generation should not interfere with the measure- 
ment of the exogenously added enzymes. Very often bovine factor $\mathrm{Xa}$ is used. It must be appreciated, however, that ionized calcium can interfere with the protein-heparin interactions taking place (Braud et al, 1980). Indeed, in reaction systems composed of purified proteins it has been demonstrated that calcium reduces the rate constants of inactivation of thrombin (Speight \& Griffith, 1983), whereas it enhances the inactivation of factor Xa (Barrowcliffe \& Shirley, 1989; Schoen et al, 1989). The latter effect is especially important in the case of human factor Xa, and the extent of this effect depends on the heparin molecular size. In addition, the anti-factor $\mathrm{Xa}$ and anti-thrombin activities assayed are expressed relative to those of a UF reference preparation $(\mathrm{U} / \mathrm{mg})$, of which the anti-factor $\mathrm{Xa}$ and antithrombin activities are per definition equal, or relative to a LMW reference preparation which has been calibrated against the UF reference preparation (Barrowcliffe et al, 1988). This approach tends to obscure the fact that in practice thrombin is inhibited much faster than factor Xa.

The point which has to be addressed at present is, to what extent does ionized calcium in the physiological range, and the presence of plasma proteins influence the rate constants of inactivation of factor $\mathrm{Xa}$ and thrombin, and the ratios of these rate constants. Therefore, we extended our previous study with purified ATIII (Schoen et al, 1991), and investigated the (LMW) heparin-dependent rate constants of inactivation of factor Xa and thrombin in the absence and presence of $1.5 \mathrm{mu}$ calcium, in a purified system and in normal human plasma.

\section{MATERIALS AND METHODS}

The 4th International Standard for heparin (UF standard heparin) and the 1st International Standard for LMW heparin (LMW standard heparin) were a kind gift of Dr T. W. Barrowcliffe from the National Institute for Biological Standards and Control (Potters Bar, U.K.). The LMW heparin preparations CY216 (batch P 795 XH), CY222 (batch P 227 WH), and the synthetic pentasaccharide (Choay et al, 1983)) were from Sanofi Recherche (Gentilly, France). Enoxaparin was from Rhône-Poulenc (Gennevilliers, France). Mean molecular weights, and anti-factor $\mathrm{Xa}$ and anti-thrombin potencies $(\mathrm{U} / \mathrm{mg})$ of these heparin preparations are given in Table I.

Normal platelet free plasma was prepared as described previously (Hemker et al, 1986). Human factor Xa and human ATIII were prepared as described previously (Schoen et al, 1990). Thrombin was isolated by chromatography of prothrombinase-activated human prothrombin on sulphopropyl-Sephadex (Pharmacia, Uppsala, Sweden), at $\mathrm{pH} 7 \cdot 4$ (Miller-Andersson et al, 1980). The molar concentrations of the factor $\mathrm{Xa}$ and thrombin preparations were determined by active site titrations with p-nitrophenyl-p'-guanidinobenzoate $\cdot$ HCl (Chase \& Shaw, 1969; Smith, 1973). The molar concentration of the ATIII preparation was assessed by titration with known amounts of factor $\mathrm{Xa}$. The proteins were stored in $50 \mathrm{~mm}$ Tris- $\mathrm{HCl}(\mathrm{pH} 7 \cdot 9)$, containing $175 \mathrm{~mm} \mathrm{NaCl}$, at $-70^{\circ} \mathrm{C}$.

ChromogenicsubstratesforfactorXa, benzoyl-L-isoleucyl-L-
Table I. Mean molecular weights, and specific potencies of the heparin preparations used in this study.

\begin{tabular}{|c|c|c|c|c|}
\hline Heparin* & $\mathrm{M}_{\mathrm{r}} \dagger$ & $\begin{array}{l}\text { a-Xa } \\
\text { activity } \\
\text { (U/mg) }\end{array}$ & $\begin{array}{l}\text { a-IIa } \\
\text { activity } \\
\text { (U/mg) }\end{array}$ & $a-X a / a-\Pi a$ \\
\hline UF St. Hep. $\ddagger$ & 12500 & 193 & 193 & $1 \cdot 0$ \\
\hline LMW St. Hep. $\ddagger$ & 6400 & 168 & 67 & $2 \cdot 5$ \\
\hline CY216§ & 5100 & 95 & 27 & $3 \cdot 5$ \\
\hline Enoxaparin§ & 3800 & 98 & 25 & $3 \cdot 9$ \\
\hline CY222ๆ & 3800 & 53 & 7 & $7 \cdot 6$ \\
\hline Pentasaccharide§ & 1715 & 1140 & 0 & $\infty$ \\
\hline
\end{tabular}

* Abbreviation: St. Hep., standard heparin.

† Determined by gel permeation HPLC, or in the case of pentasaccharide deduced from its chemical composition (Choay et al, 1983).

$\ddagger$ Anti-factor $\mathrm{Xa}$ and anti-thrombin activities as supplied by the National Institute for Biological Standards and Control (Potters Bar, U.K.).

$\S$ Anti-factor Xa and anti-thrombin activities related to those of the L.MW standard heparin (International Units/mg; personal communication, Dr T. W. Barrowcliffe).

I Anti-factor Xa and anti-thrombin activities related to those of the LMW standard heparin (Cadroy et al, 1989).

glutamyl-( $\gamma$-piperidyl)-L-glycyl-L-arginine-p-nitroanilide $\mathrm{HCl}$ (S2337) and thrombin, D-phenylalanyl-L-pipecolyl-Larginine-p-nitroanilide $\cdot 2 \mathrm{HCl}$ ( $\mathrm{S} 2238$ ) were purchased from AB Kabi Diagnostica (Stockholm, Sweden). Recombinant desulphato-hirudin variant 1 (CGP39393) was kindly provided by Dr R. Wallis from Ciba-Geigy Pharmaceuticals (Horsham, U.K.)

Inactivation of factor Xa and thrombin by purified ATIII. The heparin-catalysed inactivation of factor Xa and thrombin by purified ATIII was studied under pseudo-first order conditions at $37^{\circ} \mathrm{C}$. Either of the enzymes was added to a mixture of ATIII and heparin in $50 \mathrm{~mm}$ Tris- $\mathrm{HCl}(\mathrm{pH} \mathrm{7.9})$, containing $175 \mathrm{~mm}$ $\mathrm{NaCl}$ and $0.5 \mathrm{mg} / \mathrm{ml}$ human serum albumin (HSA), either in the absence or presence of $1.5 \mathrm{mM} \mathrm{CaCl}_{2}$. The initial protease and inhibitor concentrations were $30 \mathrm{nM}$ and $0.50 \mu \mathrm{M}$, respectively.

Following the addition of factor Xa or thrombin, four samples of $20 \mu \mathrm{l}$ each were removed within $1 \mathrm{~min}$. The residual factor Xa or thrombin activities were assayed by adding the samples to cuvettes containing $430 \mu \mathrm{l}$ of $50 \mathrm{~mm}$ Tris-HCl (pH 7.9), containing $175 \mathrm{~mm} \mathrm{NaCl}, 20 \mathrm{~mm}$ EDTA, and $0.5 \mathrm{mg} \mathrm{HSA} / \mathrm{ml}$, and $50 \mu \mathrm{l}$ of $2.2 \mathrm{~mm}$ of either $\mathrm{S} 2337$ or S2238. The conversion of chromogenic substrate was followed at $37^{\circ} \mathrm{C}$ on a dual wavelength spectrophotometer at $405 \mathrm{~nm}$ (reference wavelength $500 \mathrm{~nm}$ ), and the residual factor $\mathrm{Xa}$ and thrombin concentrations were calculated from standard curves of known amounts of the enzymes. Due to the 25-fold dilution of the samples, and the presence of excess chromogenic substrate in the cuvettes, the rates of factor Xa and thrombin neutralization became sufficiently low not to result in measurable loss of enzymatic activities during the recording of the absorbances. The residual factor Xa and thrombin activities were plotted exponentially versus reac- 
tion times, and the slopes (pseudo-first order rate constants) of the linear plots thus obtained were determined by linear regression analysis.

Inactivation of factor $\mathrm{Xa}$ and thrombin in plasma. Citrated plasma $(127 \cdot 5 \mu \mathrm{l})$ was supplemented with a small aliquot of heparin, plus $3.0 \mu \mathrm{l}$ hirudin in the case of factor $\mathrm{Xa}$ inactivation, and the volume was adjusted to $140 \mu \mathrm{l}$ with 50 $\mathrm{mm}$ Tris- $\mathrm{HCl}$ ( $\mathrm{pH} \mathrm{7.9),} \mathrm{containing} 175 \mathrm{~mm} \mathrm{NaCl}$, and $0.5 \mathrm{mg}$ $\mathrm{HSA} / \mathrm{ml}$. After a $4 \mathrm{~min}$ incubation at $37^{\circ} \mathrm{C}, 10 \mu \mathrm{l}$ factor $\mathrm{Xa}$ or thrombin with or without $\mathrm{CaCl}_{2}$ was added to final concentrations of $30 \mathrm{~nm}$ factor Xa or $50 \mathrm{~nm}$ thrombin, and $1.5 \mathrm{~mm}$ free $\mathrm{Ca}^{2+}$ in $85 \%$ plasma. It was assessed with a calciumspecific electrode system (Radiometer, Copenhagen, Denmark) that in order to obtain such a level of ionized calcium, $\mathrm{CaCl}_{2}$ had to be added to the citrated plasma to a final concentration of $15.5 \mathrm{~mm}$. Within $1 \mathrm{~min}$, timed samples of $20 \mu \mathrm{l}$ each were removed and assayed for residual factor $\mathrm{Xa}$ or thrombin as outlined above.

In factor $\mathrm{Xa}$ inactivation experiments in plasma, activation of prothrombin, followed by feedback activation of factor $V$ could occur. The large amounts of thrombin formed subsequently, would lead to significant consumption of plasma ATIII. Therefore, in these experiments hirudin (final concentration $2 \cdot 0 \mu \mathrm{M}$ ) was used to prevent clotting and consumption of ATIII. In the thrombin inactivation experiments a fibrin clot would be formed, seriously hampering sampling of the plasma. Therefore in the case of thrombin inactivation, defibrinated plasma (Hemker et al, 1986) was used. Control experiments in the absence of exogenously added factor Xa and thrombin verified that, under these conditions, both in the absence or presence of added $\mathrm{CaCl}_{2}$, no measurable generation of plasma factor Xa or thrombin occurred during at least $5 \mathrm{~min}$.

Analysis of the inactivation of factor $\mathrm{Xa}$ and thrombin in plasma. In plasma, factor $\mathrm{Xa}$ and thrombin are not only inactivated by ATIII, but also by $\alpha_{2}$-macroglobulin. Inactivation by $\alpha_{2}$-macroglobulin complicates the analysis of the inactivation curves, due to the fact that the $\alpha_{2}$-macroglobulin/protease complexes have a residual amidolytic activity towards the chromogenic substrates used. In the case of factor Xa inactivation, however, the contribution of $\alpha_{2^{-}}$ macroglobulin/factor $\mathrm{Xa}$ to the amidolytic activity measured within $1 \mathrm{~min}$, can safely be neglected due to the low rate of inactivation of exogenous factor Xa by plasma $\alpha_{2}$-macroglobulin ( $k=0.07 \mathrm{~min}^{-1}$; Jesty, 1986). Therefore, residual factor $\mathrm{Xa}$ activities were plotted exponentially versus reaction times, and the slopes (pseudo-first order rate constant) of the linear plots thus obtained were determined by linear regression analysis.

In the case of thrombin inactivation, the reaction with $\alpha_{2-}$ macroglobulin cannot be neglected. It has previously been derived (Hemker et al, 1986) that thrombin inhibition in plasma is then described by:

$$
A_{t}=A_{0}\left[C k_{2}+\left(k_{1}+k_{2}-C k_{2}\right) \mathrm{e}^{-\left(k_{1}+k_{2}\right)}\right] /\left(k_{1}+k_{2}\right)
$$

where $A_{t}$ is the amidolytic activity at time $t$, and $A_{0}$ is the initial amidolytic activity. The rate constant $k_{1}$ accounts for the (heparin-catalysed) formation of inactive thrombininhibitor complexes (thrombin-ATIII and thrombin-heparin cofactor II), and $k_{2}$ is the rate constant of the reaction between thrombin and $\alpha_{2}$-macroglobulin, where the formed complex has a fraction $(C)$ of the activity of free thrombin. Parameter $C$ was regarded as non-adjustable, with a value of 0.56 (Hemker et al, 1986). The thrombin data obtained within the 1 min inactivation periods would not allow an accurate simultaneous determination of the values of $k_{1}$ and $k_{2}$, therefore we first of all independently determined the value of $k_{2}$. Thrombin was added to plasma, and its inactivation was followed for $5 \mathrm{~min}$, revealing the $\alpha_{2}$-macroglobulin/thrombin end-level. Equation 1 was then fitted to the data by a GaussNewton least squares algorithm (Duggleby, 1981) which revealed values of $k_{2}=0 \cdot 30 \pm 0.05 \mathrm{~min}^{-1}$, and $k_{2}=$ $0 \cdot 54 \pm 0 \cdot 11 \mathrm{~min}^{-1}$ in the absence of ionized calcium and in the presence of $1.5 \mathrm{~mm}$ ionized calcium, respectively (errors represent SE values). Then we performed one-parameter fits, utilizing the same algorithm, to our data obtained during the 1 min inactivation periods in the presence of heparin. This resulted in the values of $k_{1}$, the pseudo-first order rate constants of heparin-catalysed inactivation of thrombin.

Specific anti-factor Xa and anti-thrombin catalytic activities. In each reaction system the specific anti-factor $\mathrm{Xa}$ and antithrombin catalytic activities were obtained by determining the increases of the pseudo-first order rate constants of factor $\mathrm{Xa}$ and thrombin per weight concentration of heparin. That is, the pseudo-first order rate constants of inactivation of factor $\mathrm{Xa}$ and thrombin were plotted versus the concentrations of heparin, and the slopes of the linear plots thus obtained were determined by linear regression analysis. Between four and eight experiments were used to determine the specific catalytic activities, and the reported errors represent the SE values of the estimates.

\section{RESULTS}

Rate constants of inactivation of factor Xa and thrombin by purified ATIII as function of heparin and calcium concentration Pseudo-first order rate constants of the reactions between purified ATIII and factor Xa or thrombin were determined as outlined under Materials and Methods. Fig 1 shows examples of rate constants of inactivation of thrombin obtained in the absence of calcium and in the presence of 1.5 or $4.0 \mathrm{~nm}$ calcium for increasing concentrations of UF standard heparin. The other heparin preparations were tested in the same manner, including the inactivation of factor $\mathrm{Xa}$, and the pseudo-first order rate constants of the inactivation reactions were always linearly dependent on the heparin concentrations. Slopes of such plots, the specific anti-factor Xa and antithrombin catalytic activities, are summarized in Table II.

The data in Table II show that the specific anti-factor Xa, catalytic activity of UF standard heparin is 2.4 times higher in the presence of $1.5 \mathrm{~mm}$ calcium. In contrast, the effect of calcium on the anti-factor Xa activities of the LMW heparin preparations and of the pentasaccharide is much less pronounced. While $\mathrm{Ca}^{2+}$-ions enhance the heparin-catalysed inhibition of factor Xa, they reduce the catalytic activity of heparin in the reaction of ATIII with thrombin. The presence of $1.5 \mathrm{~mm}$ calcium reduces the specific anti-thrombin catalytic activities about 1.5 times. There is some variation in 


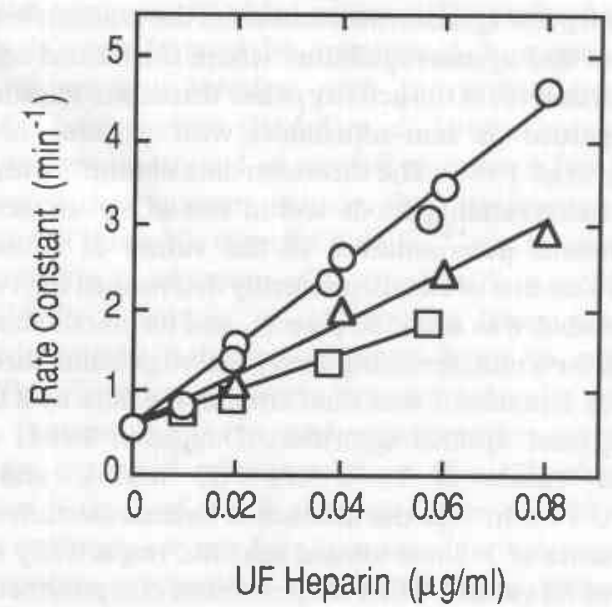

Fig 1. Rate constants of inactivation of thrombin by ATIII as function of UF standard heparin concentration. Human thrombin was added to purified ATIII in the absence of ionized calcium $(O)$, in the presence of $1.5 \mathrm{~mm}(\Delta)$ or $4.0 \mathrm{~mm}(\square)$ calcium. Pseudo-first order rate constants were determined for increasing concentrations of UF standard heparin as outlined under Materials and Methods. Solid lines were obtained by linear regression analysis of the data.

Table II. Heparin-catalysed inactivation of factor Xa and thrombin by purified ATIII.

\begin{tabular}{|c|c|c|c|}
\hline \multirow[b]{2}{*}{ Heparin } & \multicolumn{2}{|c|}{$k\left(\min ^{-1}[\mu \mathrm{g} / \mathrm{ml}]^{-1}\right)$} & \multirow[b]{2}{*}{ Ratio* } \\
\hline & No $\mathrm{CaCl}_{2}$ & $1.5 \mathrm{mM} \mathrm{Ca}^{2+}$ & \\
\hline \multicolumn{4}{|l|}{ Inhibition of factor $\mathrm{Xa}$} \\
\hline UF standard heparin & $3 \cdot 80 \pm 0 \cdot 10$ & $9 \cdot 03 \pm 0 \cdot 13$ & $2 \cdot 4$ \\
\hline LMW standard heparin & $1.75 \pm 0.03$ & $2 \cdot 91 \pm 0 \cdot 01$ & $1 \cdot 7$ \\
\hline CY216 & $0.96 \pm 0.03$ & $1 \cdot 58 \pm 0 \cdot 01$ & $1 \cdot 6$ \\
\hline Enoxaparin & $0.85 \pm 0.02$ & $1.45 \pm 0.01$ & $1 \cdot 7$ \\
\hline $\mathrm{CY} 222$ & $0.69 \pm 0.03$ & $1 \cdot 10 \pm 0 \cdot 02$ & $1 \cdot 6$ \\
\hline Pentasaccharide & $10 \cdot 2 \pm 0 \cdot 1$ & $13 \cdot 8 \pm 0 \cdot 2$ & $1 \cdot 4$ \\
\hline \multicolumn{4}{|l|}{ Inhibition of thrombin } \\
\hline UF standard heparin & $48 \cdot 7 \pm 1 \cdot 1$ & $31 \cdot 2 \pm 1 \cdot 2$ & 0.64 \\
\hline LMW standard heparin & $20 \cdot 2 \pm 0 \cdot 8$ & $13 \cdot 7 \pm 0 \cdot 6$ & 0.68 \\
\hline $\mathrm{CY} 216$ & $7 \cdot 20 \pm 0 \cdot 19$ & $4 \cdot 71 \pm 0 \cdot 13$ & 0.65 \\
\hline Enoxaparin & $6 \cdot 25 \pm 0 \cdot 05$ & $4 \cdot 64 \pm 0 \cdot 09$ & $0 \cdot 74$ \\
\hline CY222 & $2 \cdot 59 \pm 0.08$ & $1.92 \pm 0 \cdot 08$ & $0 \cdot 74$ \\
\hline Pentasaccharide§ & - & - & - \\
\hline
\end{tabular}

Human factor Xa or thrombin was added to purified ATIII either in the absence of calcium or in the presence of $1.5 \mathrm{~mm}$ calcium. Heparin concentrations were variable. The pseudo-first order rate constants of inactivation of factor $\mathrm{Xa}$ and thrombin were normalized to the heparin concentrations. See Materials and Methods for further experimental details. $\S$ At the highest concentration used to measure pentasaccharide-catalysed inactivation of factor Xa $(0.5 \mu \mathrm{g} / \mathrm{ml})$, the rate constants of inactivation of thrombin were unaffected.

* The ratio of the specific catalytic activities as obtained in the presence of calcium to those as obtained in the absence of calcium. the effect of calcium on the (LMW) heparin-catalysed inactivation of thrombin, although no clear relation seems apparent between the type of heparin and the effect of calcium.

Previous work with purified proteins (Schoen et al, 1991) was performed in the presence of $4 \cdot 0 \mathrm{~mm}$ calcium. Comparative data obtained in the present work at this level of calcium showed that no quantitative differences are observed between the inactivation of factor $\mathrm{Xa}$ in the presence of 1.5 or $4.0 \mathrm{~mm}$ calcium. Increasing the calcium levels does, however, further reduce the specific anti-thrombin catalytic activities. In the presence of $4.0 \mathrm{~mm}$ calcium the antithrombin activities were on the average about $2 \cdot 1$ times lower than in the absence of calcium. Also in these cases no apparent relation between the type of heparin and the extent of the calcium effect was noted.

\section{Effect of calcium on the inactivation of factor Xa and thrombin in plasma}

Following these results obtained with purified ATIII the question was put forward whether in plasma the inactivation of factor $\mathrm{Xa}$ and thrombin would also be sensitive to the presence of ionized calcium. To this end pseudo-first order rate constants of inactivation of factor $\mathrm{Xa}$ and thrombin were determined for increasing heparin concentrations as described under Materials and Methods. Fig 2 shows UF standard heparin-dependent rate constants obtained in the absence and presence of $1.5 \mathrm{~mm}$ calcium. The other heparin preparations were tested in the same manner, and the specific anti-factor $\mathrm{Xa}$ and anti-thrombin catalytic activities are summarized in Table III.

Also in plasma it is observed that in the presence of $1.5 \mathrm{~mm}$ calcium the specific anti-factor Xa catalytic activities are higher than in the absence of calcium. Moreover, the extent of this effect follows the same order as with purified ATIII (Table II). That is, calcium has no effect on the pentasaccharide-catalysed inactivation of factor Xa whereas the effect increases to $2 \cdot 1$-fold for the UF standard heparin-catalysed reaction. In contrast to these results, ionized calcium at a concentration of $1.5 \mathrm{~mm}$ has only a very small influence, if any, on the specific anti-thrombin catalytic activities in plasma. The results could suggest that there is a small reduction (1.1-1.3 times) of anti-thrombin activity in the presence of $\mathrm{CY} 222$ and enoxaparin. This does not indicate, however, that the inactivation of thrombin in plasma, in the presence of UF and LMW standard heparin, and CY216 is completely insensitive to the presence of calcium. When the ionized calcium concentration was increased to $4.0 \mathrm{~mm}$ the anti-thrombin catalytic activities decreased $1 \cdot 4-1 \cdot 8$-fold (data not shown).

\section{Anti-factor Xa/anti-thrombin ratios}

In each reaction system the ratio of the specific anti-factor Xa catalytic activity $\left(\mathrm{min}^{-1}[\mu \mathrm{g} / \mathrm{ml}]^{-1}\right)$ to that of thrombin was calculated for each heparin preparation. The data obtained are shown in Table IV. With purified ATIII in the absence of calcium the ratios gradually increase from 0.078 with UF standard heparin to 0.27 with CY222. Ionized calcium reduces the specific anti-thrombin catalytic activities and increases the specific anti-factor $\mathrm{Xa}$ activitities (Table II). 

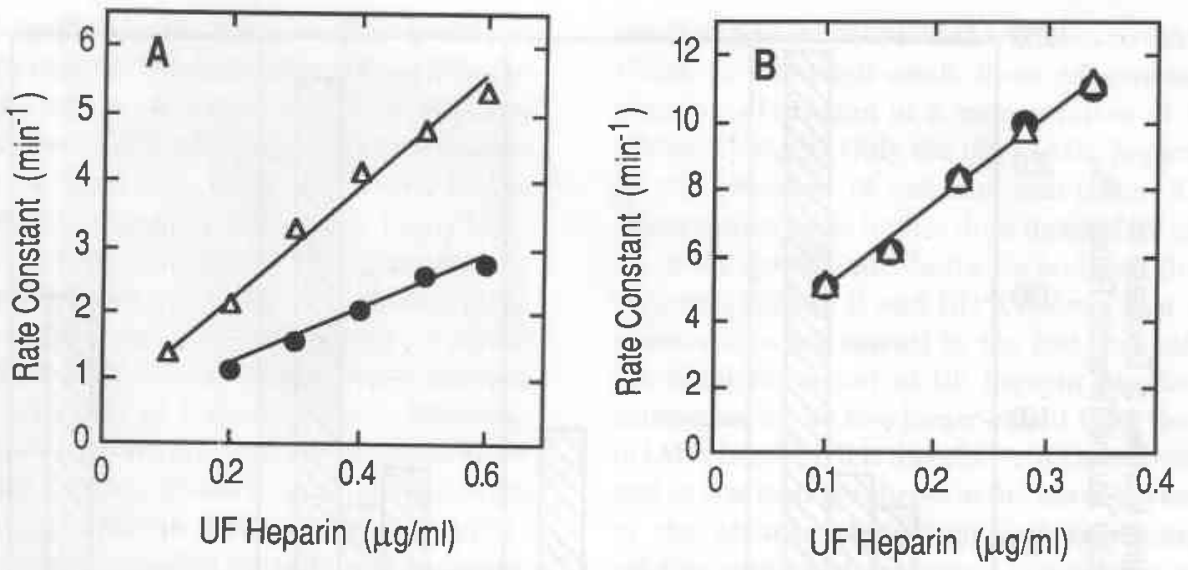

Fig 2. Rate constants of inactivation of factor Xa and thrombin in plasma as function of UF standard heparin concentration. Human factor Xa (panel A) or human thrombin (panel B) was added to human plasma in the absence $(\bullet$ ) or presence of $1.5 \mathrm{~mm}(\Delta)$ ionized calcium. Pseudo-first order rate constants were determined for increasing concentrations of UF standard heparin as outlined under Materials and Methods. Solid lines were obtained by linear regression analysis of the data.

Table III. Anti-factor Xa and anti-thrombin activities in human plasma.

\begin{tabular}{|c|c|c|c|}
\hline \multirow[b]{2}{*}{ Heparin } & \multicolumn{2}{|c|}{$k\left(\min ^{-1}[\mu \mathrm{g} / \mathrm{ml}]^{-1}\right)$} & \multirow[b]{2}{*}{ Ratio* } \\
\hline & No $\mathrm{CaCl}_{2}$ & $1.5 \mathrm{mM} \mathrm{Ca}^{2+}$ & \\
\hline \multicolumn{4}{|l|}{ Inhibition of factor $\mathrm{Xa}$} \\
\hline UF standard heparin & $3 \cdot 79 \pm 0 \cdot 21$ & $7 \cdot 97 \pm 0 \cdot 22$ & $2 \cdot 1$ \\
\hline LMW standard heparin & $2 \cdot 48 \pm 0.05$ & $3 \cdot 12 \pm 0 \cdot 05$ & $1 \cdot 3$ \\
\hline CY216 & $1 \cdot 20 \pm 0 \cdot 01$ & $1 \cdot 61 \pm 0 \cdot 03$ & $1 \cdot 3$ \\
\hline Enoxaparin & $0.85 \pm 0.02$ & $1 \cdot 09 \pm 0 \cdot 03$ & $1 \cdot 3$ \\
\hline CY222 & $0 \cdot 70 \pm 0 \cdot 02$ & $0.86 \pm 0.02$ & $1 \cdot 2$ \\
\hline Pentasaccharide & $11 \cdot 0 \pm 0 \cdot 4$ & $11 \cdot 1 \pm 0 \cdot 2$ & $1 \cdot 0$ \\
\hline \multicolumn{4}{|l|}{ Inhibition of thrombin } \\
\hline UF standard heparin & $25 \cdot 9 \pm 0 \cdot 5$ & $26 \cdot 1 \pm 0 \cdot 4$ & $1 \cdot 0$ \\
\hline LMW standard heparin & $11 \cdot 7 \pm 0 \cdot 4$ & $12 \cdot 6 \pm 0 \cdot 3$ & $1 \cdot 1$ \\
\hline CY216 & $4 \cdot 45 \pm 0 \cdot 30$ & $4 \cdot 37 \pm 0 \cdot 28$ & 0.98 \\
\hline Enoxaparin & $3 \cdot 34 \pm 0 \cdot 06$ & $2 \cdot 95 \pm 0.08$ & 0.88 \\
\hline $\mathrm{CY} 222$ & $1 \cdot 40 \pm 0 \cdot 07$ & $1 \cdot 12 \pm 0 \cdot 07$ & $0 \cdot 8$ \\
\hline Pentasaccharide§ & - & - & - \\
\hline
\end{tabular}

Human factor Xa or thrombin was added to normal human plasma in the absence or presence of $1.5 \mathrm{~mm}$ calcium. Heparin concentrations were variable. The pseudo-first order rate constants of inactivation of factor $\mathrm{Xa}$ and thrombin were normalized to the heparin concentrations. See Materials and Methods for further experimental details. $\S$ At the highest concentration used to measure pentasaccharide-catalysed inactivation of factor Xa $(0.5 \mu \mathrm{g} / \mathrm{ml})$, the rate constants of inactivation of thrombin were unaffected.

* The ratio of the specific catalytic activities as obtained in the presence of calcium to those as obtained in the absence of calcium.

Consequently, calcium increases the anti-factor Xa/antithrombin ratios. However, because the effect of calcium on the heparin-catalysed inactivation of factor $\mathrm{Xa}$ is the most pronounced with UF standard heparin, the ratio obtained with this heparin preparation increases relatively more than that of the lower molecular weight preparations. Thus, in the
Table IV. Ratios of anti-factor Xa to anti-thrombin specific activities.

\begin{tabular}{|c|c|c|c|c|}
\hline \multirow[b]{2}{*}{ Heparin } & \multicolumn{2}{|c|}{ Purified ATIII } & \multicolumn{2}{|c|}{ Plasma } \\
\hline & $\begin{array}{l}\mathrm{No} \\
\mathrm{Ca}^{2+}\end{array}$ & $\begin{array}{l}1.5 \mathrm{~mm} \\
\mathrm{Ca}^{2+}\end{array}$ & $\begin{array}{l}\text { No } \\
\mathrm{Ca}^{2+}\end{array}$ & $\begin{array}{l}1.5 \mathrm{~mm} \\
\mathrm{Ca}^{2+}\end{array}$ \\
\hline UF standard heparin & 0.078 & $0 \cdot 29$ & $0 \cdot 15$ & $0 \cdot 31$ \\
\hline LMW standard heparin & $0 \cdot 087$ & $0 \cdot 21$ & $0 \cdot 21$ & $0 \cdot 25$ \\
\hline $\mathrm{CY} 216$ & $0 \cdot 13$ & 0.34 & $0 \cdot 27$ & $0 \cdot 37$ \\
\hline Enoxaparin & $0 \cdot 14$ & $0 \cdot 31$ & $0 \cdot 25$ & $0 \cdot 37$ \\
\hline CY222 & $0 \cdot 27$ & 0.57 & $0 \cdot 50$ & 0.77 \\
\hline
\end{tabular}

Ratios of the specific anti-factor Xa and anti-thrombin catalytic activities as determined with purified ATIII (Table II) and in plasma (Table III), at variable concentrations of calcium.

presence of calcium the anti-factor $\mathrm{Xa} /$ anti-thrombin ratios of UF standard heparin, LMW standard heparin, CY216, and enoxaparin come closer to each other.

The latter observation is more clearly illustrated in Fig 3, where the increases (or decreases) of anti-factor Xa to antithrombin ratios are shown relative to the ratio as obtained with UF standard heparin. With purified ATIII in the absence of calcium, the ratios obtained with LMW standard heparin, CY216, enoxaparin and CY 222 , increase by $12 \%, 67 \%, 79 \%$ and $246 \%$, respectively. In the presence of $1.5 \mathrm{~mm}$ calcium the ratio as obtained with LMW standard heparin decreases by $27 \%$, and the ratios as obtained with CY216 and enoxaparin increase by $12 \%$ and $7 \%$. The ultra LMW heparin preparation CY222 deviates from the other LMW heparin preparations in that, although its ratio decreases due to the presence of calcium, this parameter remains significantly higher than that of UF standard heparin (increase by $97 \%$ ).

In the plasma system in the presence of $1.5 \mathrm{~mm}$ calcium the specific anti-thrombin activities are unaltered. However, the specific anti-factor $\mathrm{Xa}$ activities are in the same manner sensitive to calcium as with purified ATII (Table III). 


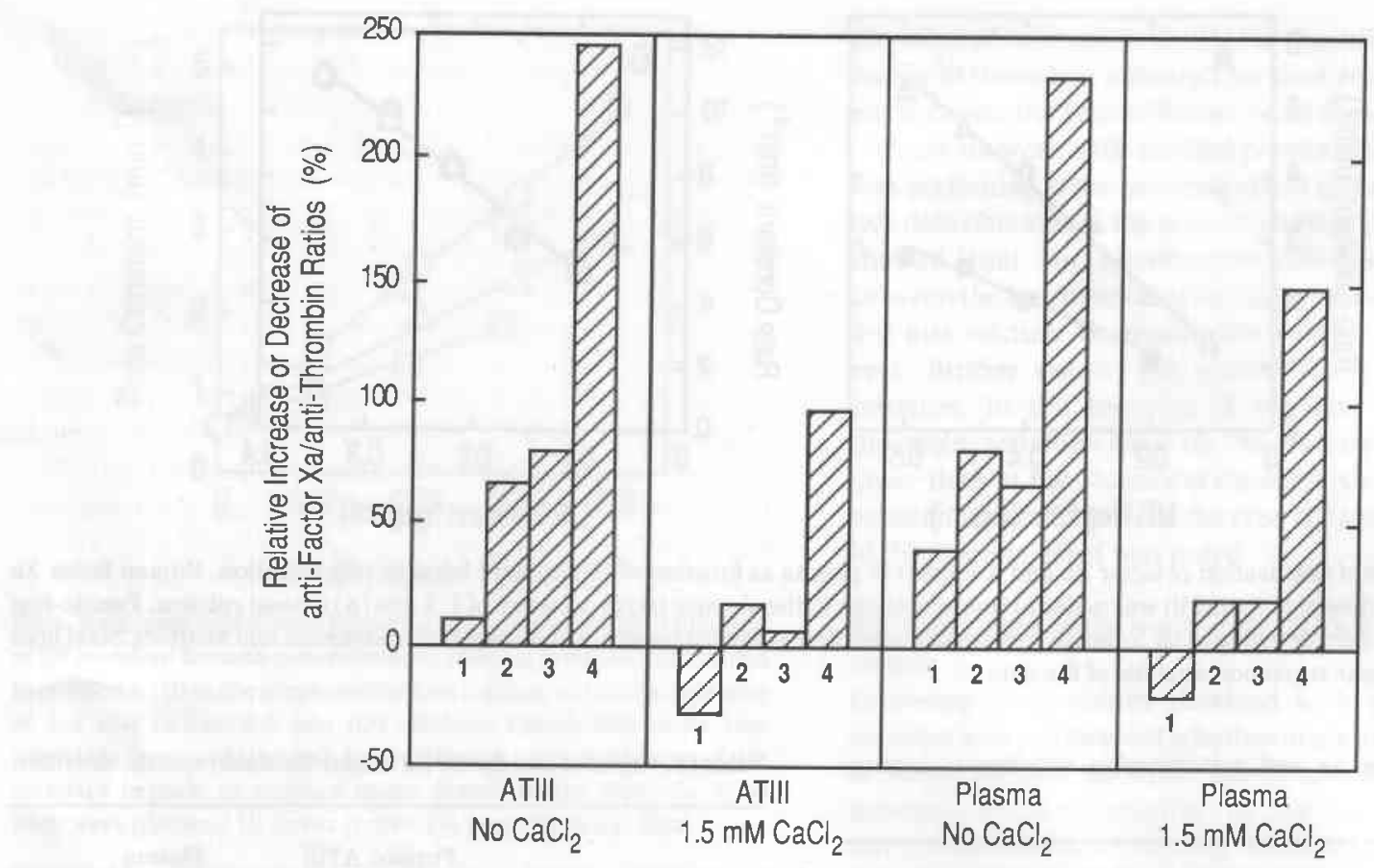

Fig 3. Relative differences in anti-factor Xa to anti-thrombin ratios. Increases (or decreases) of anti-factor Xa to anti-thrombin ratios are shown relative to the ratios as obtained with UF standard heparin (Table IV). 1. LMW standard heparin; 2, CY216; 3, enoxaparin; 4, CY222.

Therefore, also in plasma in the presence of $1.5 \mathrm{mM}$ calcium, the anti-factor Xa to anti-thrombin ratios obtained with $\mathrm{UF}$ standard heparin, LMW standard heparin, CY216, and enoxaparin approach each other (Table IV, Fig 3). In the absence of calcium, the ratios obtained with LMW standard heparin, CY216, enoxaparin and CY222, increase, respectively, by $40 \%, 80 \%, 67 \%$ and $233 \%$ relative to the ratio of UF standard heparin. In the presence of $1.5 \mathrm{~mm}$ ionized calcium the ratio as obtained with LMW standard heparin decreases by $19 \%$, and the ratios as obtained with CY216 and enoxaparin both increase by $19 \%$, relative to that of UF standard heparin. Again in this system the ultra LMW heparin preparation CY222 behaves different from the other LMW heparin preparations: in the presence of $1.5 \mathrm{~mm}$ calcium the anti-factor $\mathrm{Xa}$ to anti-thrombin ratio remains significantly higher than that of UF standard heparin (increase by $148 \%$ ).

\section{DISCUSSION}

In the current laboratory tests designed to measure antifactor Xa and anti-thrombin activities, the activities of any heparin preparation are expressed relatively to those of an International Standard preparation. The unitage used is $\mathrm{U} / \mathrm{mg}$, and it has been agreed that the anti-factor Xa and antithrombin activities of the UF heparin standard preparations are equal. Although this approach is relatively simple and easy to comprehend, it gives no information about the true inactivation rates obtained with heparins in the reaction with factor Xa and thrombin. Moreover, as the relative activities of heparin in plasma can vary both with the type of heparin and the assay conditions this practice may introduce non-existing differences between heparin preparations. Therefore we used a standard independent method, i.e. the directly measurable apparent first order rate constants of inactivation of factor Xa and thrombin, which give the absolute activities of the heparin preparations under well-defined conditions.

Following this approach we measured the heparin-catalysed inactivation of human factor Xa and human thrombin with purified human ATIII and normal human plasma, both in the absence and presence of calcium at a level in the physiologic range ( $1.5 \mathrm{~mm}$ ). Pseudo-first order rate constants of inactivation of factor Xa and thrombin were determined as function of the concentrations of heparin (cf. Figs 1 and 2) which revealed the specific anti-factor Xa and anti-thrombin catalytic activities (Tables II and III). In the case of factor Xa inactivation in plasma, ATIII is the only inhibitor whose activity is known to be catalysed by heparin. In this respect, it is of interest to note that although the ATIII concentration employed in the purified system is significantly lower than the plasma ATIII concentration $(0.50 v . \sim 2 \mu \mathrm{M})$, comparable specific anti-factor Xa activities were found for each heparin in the two reaction systems. It therefore seems likely that under both conditions all ATIII high-affinity binding sites available on the heparin molecules are saturated with ATIII.

The latter notion could seem to contrast previous work by others (Lane et al, 1984: MacGregor et al, 1979, 1980). However, Lane and co-workers used an ATIII concentration of about $170 \mathrm{~nm}$ in their purified system, and compared these data with a plasma system. In the work of MacGregor either plasma was diluted 20 -fold (ATIII $\approx 100 \mathrm{nM}$; MacGregor $e t$ al, 1979), or 57 пм ATIII was used (MacGregor et al, 1980). Thus, deviations between their and our results may be well accounted for by differential experimental conditions. 
In the case of thrombin inactivation in the absence of calcium it is observed that the catalytic effects of the different heparin preparations are in plasma about half of those determined with purified ATIII, although plasma also contains heparin cofactor II, which could contribute to the heparin-catalysed inactivation of thrombin. The latter, however, seems to occur at heparin concentrations above those employed in this work (Bray et al, 1989; Tollefsen et al, 1990). It must be noted then, that the heparin-catalysed ATIII-dependent inactivation of thrombin heavily depends on the simultaneous binding of both proteins to the same heparin molecule (Olson, 1988). It is well feasible, that due to competition by other plasma proteins (e.g. histidine-rich glycoprotein, vitronectin, and/or lipoproteins) the ATIIIheparin-thrombin ternary complex formation is seriously hampered in the plasma system in the absence of calcium. Conversely, it is possible that calcium corrects for this effect, as addition of calcium (1.5 $\mathrm{mm})$ reduces the differences between the specific anti-thrombin catalytic activities in plasma and with purified ATIII.

Calcium increases the heparin-dependent rate constants of inactivation of factor $\mathrm{Xa}$ by purified ATIII, where no quantitative difference is found between 1.5 and $4.0 \mathrm{nM}$ calcium. This is in accordance with previous work on the effect of $\mathrm{CaCl}_{2}$ on the anti-factor Xa activity of heparin and its molecular weight fractions, in which it was found that there was an increase in potentiating effect between 0 and $1 \mathrm{~mm}$, with no further increase between 1 and $5 \mathrm{~mm}$ (Barrowcliffe \& Shirley, 1989). In that study it was also reported that as the number of heparin molecules with $M_{r}>6500$ increase, the effect of the presence of calcium increases concomitantly. The data in Table II are in the same line. As the mean molecular weights increase, thus as the numbers of molecules with $M_{r}>6500$ increase, the potentiating effects of calcium increase. There is, however, a major difference between the observations made with oligosaccharides with $M_{r}<6000$. Whereas Barrowcliffe \& Shirley (1989) demonstrated an inhibitory effect of calcium on the catalytic activity of these oligosaccharides, we failed to observe this with the CY222 preparation and the pentasaccharide, both in the presence of 1.5 and $4.0 \mathrm{~mm}$ calcium. Whether this is a fundamental difference, or due to variability of the experimental settings is unclear.

On the other hand, calcium in a concentration-dependent manner inhibits the catalytic activity of heparin in the reaction with thrombin. This is essentially identical to the results of Speight \& Griffith (1983), who also found a concentration dependent effect of calcium in the inactivation of thrombin with purified ATIII, when going from no calcium to $10 \mathrm{~mm}$ calcium. In their work they concluded that calcium binds to functional groups within the heparin molecule which are required for thrombin binding. If this is the case one could expect to find no major effect of heparin chain length on the modulating effect of calcium. Indeed this seems to be the case (Table II).

Overall, with purified ATIII in the absence of calcium, and in citrated plasma we obtained higher anti-factor Xa/antithrombin ratios with the LMW heparin preparations than with UF standard heparin. These differences, however, are smaller than those obtained with the current laboratory tests (Table I). Although small, these differences decrease in the presence of calcium at a concentration of 1.5 and $4.0 \mathrm{~mm}$ (Table IV, Fig 3). Only the ultra L.MW heparin CY222 shows in the presence of calcium anti-factor $\mathrm{Xa} /$ anti-thrombin ratios significantly higher than those of UF standard heparin. From the specific anti-factor Xa and anti-thrombin catalytic activities (Tables II and III) it follows that in essence these observations are caused by the fact that calcium stimulates the catalytic action of UF heparin on the inactivation of human factor $\mathrm{Xa}$ to a larger extent than the catalytic action of LMW heparin. It is therefore our conclusion that for in vitro and $e x$ vivo testing of heparin the use of bovine clotting factors in the absence of calcium and expressing the potencies relative to those of a reference preparation, gives no relevant information on the true anti-factor $\mathrm{Xa}$ and anti-thrombin inactivation rates for (LMW) heparin preparations.

\section{ACKNOWLEDGMENTS}

We thank Jo Franssen for excellent technical assistance, and we are grateful to Dr B. van Kreel, from the Academic Hospital in Maastricht, whose laboratory expertly performed the measurements of ionic calcium in plasma.

\section{REFERENCES}

Andersson, L.O., Barrowcliffe, T.W., Holmer, E., Johnson, E.A. \& Sims, G.E.C. (1976) Anticoagulant properties of heparin fractionated by affinity chromatography on matrix-bound antithrombin III and by gel filtration. Thrombosis Research, 9, 575-583.

Barrowcliffe, T.W., Johnson, E.A., Eggleton, A., Kemball-Cook, G. \& Thomas, D.P. (1979) Anticoagulant activities of high and low molecular weight heparin fractions. British Journal of Haematology. 41, 573-583.

Barrowcliffe, T.W., Curtis, A.D., Johnson, E.A. \& Thomas, D.P. (1988) An international standard for low molecular weight heparin. Thrombosis and Haemostasis, 60, 1-7.

Barrowcliffe, T.W. \& Shirley, Y.L. (1989) The effect of calcium chloride on anti-Xa activity of heparin and its molecular weight fractions. Thrombosis and Haemostasis, 62, 950-954.

Béguin, S., Dol, F. \& Hemker, H.C. (1991) Factor IXa inhibition contributes to the heparin effect. Thrombosis and Haemostasis, 66, 306-309.

Braud, C., Villiers, C. \& Vert, M. (1980) Counter-ion dependence in salt-containing, aqueous solutions of heparin. Carbohydrate Research, 86, 165-175.

Bray, B., Lane, D.A., Freyssinet, J.M., Pejler, G. \& Lindahl, U. (1989) Anti-thrombin activities of heparin. Effect of saccharide chain length on thrombin inhibition by heparin cofactor II and antithrombin. Biochemical Journal, 262, 225-232.

Cadroy, Y., Harker, L.A. \& Hanson, S.R. (1989) Inhibition of plateletdependent thrombosis by low molecular weight heparin (CY222): Comparison with standard heparin. Journal of Laboratory and Clinical Medicine, 114, 349-357.

Chase, T. \& Shaw, E. (1969) Comparison of the esterase activities of trypsin, plasmin and thrombin on guanidinobenzoate esters. Titration of the enzymes. Biochemistry, 8, 2214-2224.

Choay, J. (1989) Structure and activity of heparin and its fragments: an overview. Seminars in Thrombosis and Hemostasis, 15, 359-364.

Choay, J., Petitou, M., Lormeau, J.C., Sinaẏ, P., Casu, B. \& Gatti, G. (1983) Structure-activity relationship in heparin: a synthetic 


\section{2}

Pieter Schoen et al

pentasaccharide with high affinity for antithrombin III and eliciting high anti-factor Xa activity. Biochemical and Biophysical Research Communications, 116, 492-499.

Danielsson, A., Raub, E., Lindahl, U. \& Björk, I. (1986) Role of ternary complexes, in which heparin binds both antithrombin and proteinase, in the acceleration of the reactions between antithrombin and thrombin on factor Xa. Journal of Biological Chemistry, 261, 15467-15473.

Duggleby, R.G. (1981) A nonlinear regression program for small computers. Analytical Biochemistry, 110, 9-18.

Harpel, P.C. (1987) Blood proteolytic enzyme inhibitors: their role in modulating coagulation and fibrinolytic enzyme pathways. Hemostasis and Thrombosis. Basic principles and clinical practice (ed. by R. W. Colman, J. Hirsh, V. J. Marder and E. W. Salzman), pp. 219-234. J. B. Lippincott Company, Philadelphia.

Hemker, H.C., Willems, G. \& Béguin, S. (1986) A computer assisted method to obtain the prothrombin activation velocity in whole plasma independent of thrombin decay processes. Thrombosis and Haemostasis, 56, 9-17.

Jesty, J. (1986) Analysis of the generation and inhibition of activated coagulation factor $\mathrm{X}$ in pure systems and in human plasma. Journal of Biological Chemistry, 261, 8695-8702.

Lane, D.A., Macgregor, I.R., Michalski, R. \& Kakkar, V.V. (1978) Anti-coagulant activities of four unfractionated and fractionated heparins. Thrombosis Research, 12, 257-271.

Lane, D.A., Denton, J., Flynn, A.M., Thunberg, L. \& Lindahl, U. (1984) Anticoagulant activities of heparin oligosaccharides and their neutralization by platelet factor 4 . Biochemical Journal, 218 , $725-732$.

MacGregor, I.R., Lane, D.A. \& Kakkar, V.V. (1979) Evidence for a plasma inhibitor of the heparin accelerated inhibition of factor Xa by antithrombin III. Biochimica et Biophysica Acta, 586, 584-593.
MacGregor, I.R., Lane, D.A. \& Kakkar, V.V. (1980) The anti-heparin properties of human low-density lipoprotein. Biochimica et Biophysica Acta, 617, 472-479.

Miller-Andersson, M., Gaffney, P.J. \& Seghatchian, M.J. (1980) Preparation and stability of a highly purified human thrombin standard. Thrombosis Research. 20, 109-122.

Olson, S.T. (1988) Transient kinetics of heparin-catalyzed protease inactivation by antithrombin III. Linkage of protease-inhibitorheparin interactions in the reaction with thrombin. Journal of Biological Chemistry. 263, 1698-1708.

Schoen, P., Lindhout, T., Willems, G. \& Hemker, H.C. (1989) Antithrombin III-dependent anti-prothrombinase activity of heparin and heparin fragments. Journal of Biological Chemistry, 264, 10002-10007.

Schoen, P., Wielders, S., Petitou, M. \& Lindhout, T. (1990) The effect of sulfation on the anticoagulant and antithrombin III-binding properties of a heparin fraction with low affinity for antithrombin III. Thrombosis Research, 57, 415-423.

Schoen, P., Lindhout, T., Franssen, J. \& Hemker, H.C. (1991) Low molecular weight heparin-catalyzed inactivation of factor Xa and thrombin by antithrombin III. Effect of platelet factor 4 . Thrombosis and Haemostasis, 66, 435-441.

Smith, R.L. (1973) Titration of activated bovine factor X. Journal of Biological Chemistry, 248, 2418-2423.

Speight, M.O. \& Griffith. M.J. (1983) Calcium inhibits the heparincatalyzed antithrombin III/thrombin reaction by decreasing the apparent binding affinity of heparin for thrombin. Archives of Biochemistry and Biophysics, 255, 958-963.

Tollefsen, D.M., Sugimori, T. \& Maimone, M.M. (1990) Effect of low molecular weight heparin preparations on the inhibition of thrombin by heparin cofactor II. Seminars in Thrombosis and Hemostasis, 16, (Suppl.), 66-70. 